Niğde Ömer Halisdemir Üniversitesi Mühendislik Bilimleri Dergisi
Niğde Ömer Halisdemir University Journal of Engineering Sciences
ISSN: 2564-6605
Araştırma / Research

\title{
Cam elyaf takviyeli polyester (CTP) profillerden oluşan tek eğrilikli uzay kafes kirişlerin yapay sinir ağları ile analizi
}

\section{Analysis of single-curved space cage beams consisting of glass fiber reinforced polyester(GFRP) profiles with artificial neural networks}

\author{
Ahmet Arslan 1,* (D), Metin Hakan Severcan ${ }^{1}$ (ib \\ ${ }^{1}$ Niğde Ömer Halisdemir Üniversitesi, İnşaat Mühendisliği Bölümü, 51240, Niğde Türkiye
}

\section{Özet}

Bu çalıșmada cam elyaf takviyeli polyester (CTP) malzeme kullanılarak üretilen profillerin tek ĕgrilikli uzay kafes sistemlerde kullanımı incelenmiştir. Farklı sistem davranışlarını görmek üzere 20 farklı sistem modeli tasarlanmiștır. Tasarlanan sistemlerde 12 farkl yükleme kullanılarak oluşturulan toplam 240 farklı model, SAP 2000 programı ile statik olarak analiz edilmiş ve AISC-ASD89' a göre de boyutlandırılmıştır. Boyutlandırlan çubuk elemanların minimum kesit alanı değerleri, 12 farklı girdi değişkeni kullanılarak yapay sinir ağlarl yönteminde gelistirilen model ile tahmin edilmiş ve analiz sonuçlarına yakın değerler elde edilmiştir. Bu çözümler sonunda Cam elyaf takviyeli polyester malzemenin yapı malzemesi olarak tek eğrilikli uzay kafes sistemlerde diğer yapı malzemelerine ikame olarak kullanılabileceği gözlemlenmiştir.

Anahtar kelimeler: Cam elyaf takviyeli polyester, Tek eğrilikli uzay kafes sistemler, Yapay sinir ağları, AISC-ASD89

\section{Giriş}

Uzay kafes sistemler üç farklı düzlemde bulunan çubuk elemanların bir mafsal kürede birleşmesiyle oluşan ve sistem olarak üç doğrultuda da çalışan hiperstatik modüler sistemlerdir. Uzay kafes sistemler hafif, rijit ve hiperstatiklik derecesi yüksek olduğundan sistemdeki herhangi bir çubukta meydana gelebilecek bir kopma veya burkulmadan tüm yapı etkilenmemektedir. $\mathrm{Bu}$ sistemlerin hiperstatiklik derecelerinin yüksek olması, sistem içinde yük dağılımının sürekli olmasını sağlaması açısından bir avantajdır. Uzay kafes sistemler minimum malzeme ile maksimum verimin alındığı yapısal taşıyıcı sistemlerdir [1].

Uzay kafes taşıyıcı sistemler, temel biçimleri ve oluşum ilkeleri açısından incelenebilir. Bunlardan biri de tek eğrilikli tonoz şeklindeki uzay kafes sistemlerdir. Bu çalışmada yapı sistemi olarak tek eğrilikli uzay kafes sistemler kullanılmıştır.

20. yüzyılda, yapı sistemlerindeki hızlı ve olumlu gelişmeler neticesinde, yüksek yapıların yapılması ve büyük açıklıkların geçilmesinde tercih edilmiştir. Çeliğin ana malzeme olarak kullanıldığ belki de en önemlisi uzay kafes sistemlerdir. Ülkemizin, bütün dünyanın en etkili deprem kuşaklarından birisi olan Kuzey Anadolu fay hattının üzerinde olmasından dolayı

\begin{abstract}
In this study, the use of profiles produced using glass fiber reinforced polyester (GFRP) material in single curvature space cage systems was investigated. 20 different system models are designed to see different system behaviors. A total of 240 different models created by using 12 different loadings in the designed systems were statically analyzed with the SAP 2000 program and designed according to AISC-ASD89. Using 12 different input variables, the minimum cross-sectional area values of the designed cage elements were estimated with the model developed in the artificial neural network method and values close to the analysis results were obtained. At the end of these solutions, it has been observed that glass fiber reinforced polyester material can be used as a building material as a substitute for other building materials in single curvature space cage systems.

Keywords: Glass fiber reinforced polyester, Single curvature space cage
\end{abstract} system, Artificial neural networks, AISC-ASD89

depreme dayanıklı yapı araştırmaları tüm dünyada olduğu gibi ülkemizde de önem kazanmıştır [2].

Deprem hareketi olarak bilinen ivme tam anlamıla kontrol altına alınamamaktadır. Fakat yapı kütlesinin hafifletilmesi ile orantılı olarak yapıya etkiyen deprem yükü azaltılabilir. $\mathrm{Bu}$ durum göz önüne alınarak, depreme dayanıklı yapı ihtiyacını karşılayabilmek için ikame teknolojik ürünler araştırılmaktadır. En son teknolojik ürünlerden birisi de, çelik yapı malzemesine göre daha hafif, korozyon dayanımı yüksek olan cam elyaf takviyeli polyester (CTP) malzemelerdir [3].

CTP uygulamalarının üstün yanları özetlenecek olursa en başta yüksek mukavemet gelmektedir. CTP yüksek mukavemete sahip malzemeler arasında en etkili olanlardan bir tanesidir. CTP'ler birim alan ağırlığına göre takviyesiz plastikler ve metallere göre çok daha yüksek mukavemet değerlerine sahiptir.

CTP ürünlerin tüm meslek grupları tarafından yaygın olarak kabul görmesinin en önemli nedeni sağlamış olduğu yüksek performanstır. CTP malzemeler hem tüketicilerin hem de üreticilerin kullanımında çeşitli yararlar sağlamaktadır.

Yapay sinir ağları (YSA) yöntemleri son yıllarda birçok mühendislik uygulamasında yaygın olarak kullanılan bir yöntemdir [4]. Özellikle inşaat mühendisliği

\footnotetext{
* Sorumlu yazar / Corresponding author, e-posta / e-mail: ahmetarslann@ @otmail.com (A. Arslan) Geliş / Recieved: 23.10.2020 Kabul/ Accepted: 02.12.2020 Yayımlanma / Published: 15.01.2021 doi: $10.28948 /$ ngmuh.815736
} 
uygulamalarında çok yaygın olarak kullanılmaktadır [5]. Daha önce yapılmış deneysel ya da teorik çalışmalardan yararlanılarak YSA ile geliştirilen modellerle birçok ham maddenin yâda sistemin özelikleri çok kısa bir zamanda tahmin edilebilmekte ve genelleştirme yapılabilmektedir.

$\mathrm{Bu}$ çalışmada, uzay kafes sistemlerde çelik yapı malzemesi yerine CTP yap1 malzemesinin kullanımı incelenmiştir. $\mathrm{Bu}$ inceleme yapılırken de farklı sistem davranışlarını görmek üzere, 20 farklı sistem modeli tasarlanmıştır. Bu tasarlanan sistemlerde 12 farklı yükleme kullanılarak toplam 240 farklı modelin, SAP 2000 [6] programı ile statik analizi yapılmış ve AISC-ASD89' e [7] göre de boyutlandırılmıştır. Yapılan analiz ve boyutlandırma sonucunda elde edilen teorik sonuçlar kullanılarak YSA'da modeller geliştirilmiş ve geliştirilen modellerle daha farklı sistemlerin çözümlerinin çok kısa bir zamanda tahmin edileceği görülmüştür.

\section{Materyal ve metot}

\subsection{Cam elyaf takviyeli polyester profiller}

İki ya da daha fazla farklı fiziksel ve kimyasal özelliklere sahip malzemelerin birleştirilmesiyle elde edilen ürün kompozit malzeme olarak tanımlanır [8]. Günümüzde en fazla kullanılan lifli kompozit malzemelerin başında cam fiber takviyeli reçine, karbon fiber ve cam elyaf takviyeli polyesterlerdir. Şekil 1'de verilmiş olduğu gibi kompozitler takviye (reinforcement) ve reçine (matrix) bileşenleriyle oluşturulur. Bu malzeme türüne en genel örnek, "fiberglass" olarak bilinen cam fiber takviyeli polyesterdir [9].

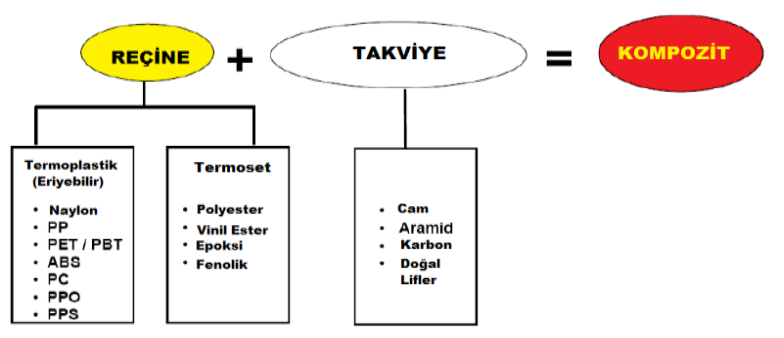

Şekil 1. Kompozit malzeme bileşenleri

Kompozit malzemelerin en yaygın kullanılanı elyaf takviyeli kompozitlerdir. Bu kompozitler malzemelerde de takviye malzemesi olarak cam tercih edilmiştir. Plastik reçineler en yaygın olarak kullanılan matriks malzemesidir. Plastik reçineler içerisinde de maliyetinden dolayı polyester tercih edilmektedir. Epoksi reçine ise yüksek gerilme dayanımı ve kimyasal dayanıklılığından dolayı yaygın bir kullanım alanı bulmaktadır [10].

$\mathrm{Bu}$ çalışmada yapı malzemesi olarak seçilen cam elyaf takviyeli polyester malzeme, Pultrüzyon üretim yöntemi ile üretilen malzemeden seçilmiştir.

\subsubsection{Pultrüzyon yöntemi}

Profillerin yapı sisteminde taşıyıcı eleman olarak kullanılabilmesi için gereken gerilme kuvvetlerine karşı direnç gösterebilmesi ve ekonomik bir biçimde üretebilmek için pultrüzyon yöntemi geliştirilmiştir. Bu yöntemle boru, kutu, L, T, I ve U profillerine ek olarak düzgün şekilli olmayan profiller de üretilebilmektedir [9].
Pultrüzyon yöntemi, malzemenin kalıp boyunca çekilerek üretilmesi dışında, termoplastik ve alüminyumun imal edilmesinde kullanılan ekstrüzyon imalat sürecine benzemektedir. Pultrüzyon da cam elyafi takviye malzemesi olarak kullanılmaktadır. Dahası mütemadi fitil, keçe ya da bu malzemelerin kombinasyonlarının bir veya birkaçı birlikte kullanılmaktadır. Fitil sehpaları elyaf, fitil ve keçelerin sarılı olduğu bobinlerin bulunduğu kısımdır. Bu bölüm pultrüzyon makinesinden ayrı bir kısımdır ve buradaki elyaf bobinlerinin sayısı, önceden mekanik özellikleri belirlenen ve üretilmek istenen malzemeye göre değişiklik gösterir. Elyafın hacim oranları \% 50 ile \% 80 arasında değişiklik gösterebilir. Üretimde öncelikle termoset; reçine banyosundan geçirilir, daha sonra şekillendirme yapan kılavuzdan geçirilir. Daha önce 1sıtılan çelik kalıp içinden geçirilerek, belirlenen kesitte sertleşmesi sağlanır. Kalıptan çıkan mamüller kesme aparatlarıyla belirtilen uzunluklarda kesilir ve üretim tamamlanır [11].

$\mathrm{Bu}$ yöntemde kullanılmakta olan reçine malzemesinin \%90'1nı polyesterler ve viniller oluşturmaktadır. Farklı performans özelliklerine sahip olması istenen malzemelerin kalıplanmasında epoksiler ile fenolik reçineler kullanılmaktadır. Fenolik reçineler, pultrüzyon üretim metodu ile üretilen mamüllere düşük duman yayma ve yanmazlık özelliklerini kazandırır. Epoksiler ise yüksek rijitlik, yüksek ısıya karşı dayanım ve yüksek elektriksel özellik performansı sağlamaktadır. Bunun yanı sıra katkılar ve dolgu malzemeleri, ürüne farklı ve çeşitli özellikler kazandırmak, imalat karakteristiklerini geliştirmek ve üretim maliyetini düşürmek amacıyla pultrüzyon yönteminde kullanılmaktadır [9].

Pultrüzyon, yön verilmiş elyafların kullanıldığı bir yöntemdir. Elyaf malzemenin çoğunluğu optimum seviyede çekme dayanımı kazanacak şekilde boyuna yerleştirilir. Hem makineleşmiş hem otomatikleşmiş düşük bir imalat işçiliği mevcuttur. İşçilik toplam maliyetin \%5 ile \%10’u arasındadır. $\mathrm{Bu}$ yöntemde ilk tesis maliyeti diğer yüksek miktarlı imalat yapılan yöntemlere göre daha düşüktür. Tüm bunlar düşünüldüğünde orta ve yüksek ölçekli uygulama alanları için bu yöntem ekonomik olmaktadır. Şekil 2'de pultrüzyon metodu ile üretilmiş bir profilin katmanları gösterilmiştir. Pultrüzyon üretim sürecinde elyaf ağırlıklı olarak çekme dayanımını arttıracak yönde yerleştirilmiş olmasından dolayı, çapraz kuvvetlere karşı mukavemeti düşüktür. Genellikle farklı yönler için sağlanan özellikler, çekme dayanımının \%10 ile \%25'i arasındadır. Pultrüzyon ürünleri genellikle rekabet halinde oldukları malzemelerle aynı rijitlik değerlerine sahip değillerdir. Bu durum rakip malzemelerin rijitlik değerlerine ulaşmak için kesitte ya da et kalınlığında tasarım değişikliklerinin yapılmasını zorunlu kılmaktadır [12].

\subsection{Yapay sinir ă̆ları}

Yapay zekâ uygulamalarından biri olan yapay sinir ağları (YSA), insan beyninin çalışma yapısını taklit ederek mevcut verileri analiz edip, bu verilerden farklı öğrenme algoritmaları ile yeni bilgiler oluşturan bilgi işlem teknolojisidir. Genel olarak YSA insan beyninin biyolojik sinir yapısını taklit ederek sinirsel algılayıcılar yardımı ile 
önceden öğrenilmiş ya da sınıflandırılmış bilgileri kullanarak yeni bilgiler türetebilen ve oluşturabilen, karar verebilen bilgisayar programlarıdır. Örüntü tanıma, sistem tanılama, robotik, sinyal işleme, nonlineer denetim alanları gibi birçok uygulama alanında yapay sinir ağları yaygın olarak kullanılmaktadır [13].

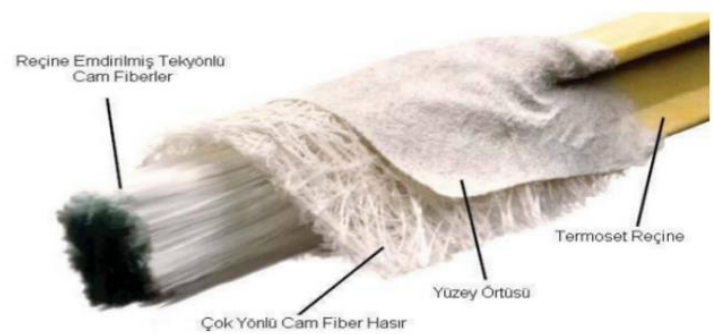

Şekil 2. Pultrüzyon metodu ile üretilmiş profil detayı

Teknik açıdan yapay sinir ağının görevi, girdi seti olarak kendisine verilen bilgilere karşılık Şekil 3'de verildiği gibi bir çıktı üretebilmektir. Bunun yapılabilmesi için ağ belirli örneklerle eğitilir. Sonra ağ genelleme yapabilecek ve karar verebilecek seviyeye kavuşur. Daha sonra bu kazanılan yetenek ile çıktıları belirler [14]. Bu çıktıların doğruya en yakın sonucu verebilmesi için girdilerin çeşitliliği ve sayısı çok önemlidir. Girdi değeri ne kadar fazla ve çeşitli ise doğru çıktıya ulaşma oranı o kadar yüksektir. YSA, paralel dağıtılmış ağlar, bağlantılı ağlar, nuromorfik ağlar gibi adlarla da tanımlanmaktadır.

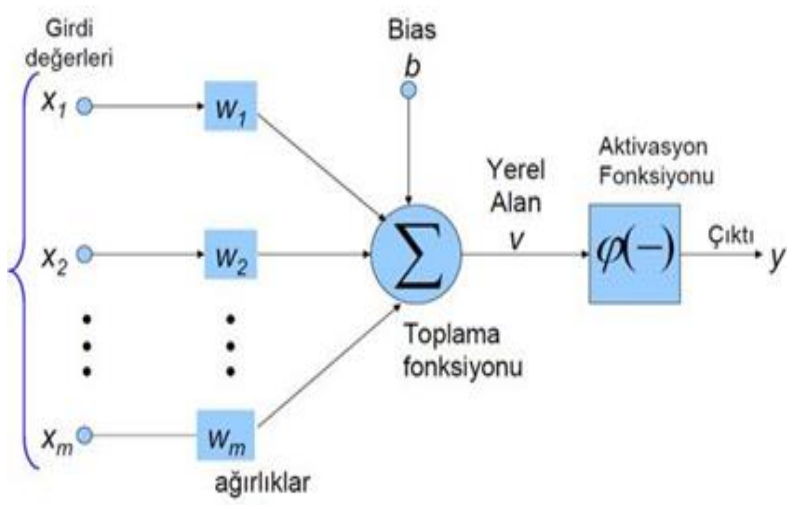

Şekil 3. Yapay sinir ağı örneği

\subsection{Tek eğrilikli uzay kafes sistemlerin analizi ve boyutlandırılmast}

Cam elyaf takviyeli polyester profiller kullanılarak oluşturulan tek eğrilikli uzay kafes sistem çubuklarının standart kesit alanları için farklı sistemlere ve çözümlerine ihtiyaç duyulmaktadır. Bu sebepten dolayı öncelikle sistem modül şekli ve sayısı sabit olması koşulu ile sistem açıklıkları ve yükseklikleri değiştirilerek 20 farklı sistem ölçüsü belirlenmiştir. Sistemlerin modül sayısı ve mimarisi aynı olduğu için sistem uzunluğu modüldeki çubuk elemanların uzaması ya da kısalmasına bağlı olarak değişmektedir. Seçilen sistem ölçüleri Tablo 1'de belirtilmiştir.
Sistemler Şekil 4'de görüldüğü gibi tonoz biçiminde tek eğrilikli bir uzay kafes sistemler olup, sistem geometrisi gereği her düğüm noktası için çatı düzlemi açıları değişmektedir. Sistemlerin kendi içerisinde değişen çatı eğimlerinden dolayı Şekil 5'de görüldüğü gibi 24 düğüm noktasına gelen yükler ayrı ayrı hesaplanmıştır. Yük hesapları yapılıp belirlendikten sonra SAP 2000 v16 [6] programı kullanılarak sistemlerin statik analizleri ve boyutlandırılmaları yapılmıştır.

Tablo 1. Örnek sistemlerin ölçüleri

\begin{tabular}{cccccc}
\hline S.No & Genişlik & Yükseklik & Uzunluk & $\begin{array}{c}\text { Modül } \\
\text { genişliği }\end{array}$ & $\begin{array}{c}\text { Modül } \\
\text { yüksekliği }\end{array}$ \\
\hline 1 & 40.0 & 10.0 & 56.50 & 1.883 & 1.017 \\
2 & 45.0 & 10.0 & 62.07 & 2.069 & 1.021 \\
3 & 40.0 & 12.0 & 59.55 & 1.985 & 1.051 \\
4 & 45.0 & 12.0 & 64.83 & 2.161 & 1.090 \\
5 & 50.0 & 12.0 & 70.00 & 2.333 & 1.195 \\
6 & 50.0 & 15.0 & 74.37 & 2.479 & 1.301 \\
7 & 55.0 & 12.0 & 75.42 & 2.517 & 1.319 \\
8 & 55.0 & 15.0 & 79.53 & 2.651 & 1.405 \\
9 & 60.0 & 15.0 & 84.81 & 2.827 & 1.495 \\
10 & 60.0 & 17.5 & 88.47 & 2.949 & 1.570 \\
11 & 65.0 & 15.0 & 90.24 & 3.008 & 1.585 \\
12 & 65.0 & 17.5 & 95.67 & 3.189 & 1.650 \\
13 & 70.0 & 17.5 & 98.94 & 3.298 & 1.739 \\
14 & 70.0 & 20.0 & 102.57 & 3.419 & 1.814 \\
15 & 75.0 & 17.5 & 104.37 & 3.479 & 1.829 \\
16 & 75.0 & 20.0 & 107.61 & 3.587 & 1.984 \\
17 & 80.0 & 20.0 & 113.07 & 3.769 & 1.983 \\
18 & 80.0 & 22.5 & 116.67 & 3.889 & 2.068 \\
19 & 85.0 & 20.0 & 118.50 & 3.950 & 2.083 \\
20 & 85.0 & 22.5 & 121.89 & 4.063 & 2.148 \\
\hline “Ölçüler m’dir” & & & & \\
\hline
\end{tabular}

Bu çalışmada yükleme değerleri ile ilgili kabuller için TS 498'den [15] yararlanılmıştır. Aynı olan her sistem için 4 farklı yükleme bölgesi seçilmiştir. Bu seçilmiş olan yükleme bölgelerinde de yine 3 ayrı rüzgâr yükü hesaplanmıştır. Bu şekilde 20 farklı sistem için 4 ayrı yükleme bölgesi ve bunlar içinde 3 ayrı rüzgâr yükü ile birlikte 240 farklı sistem analiz edilmiş ve kesitleri belirlenmiştir.

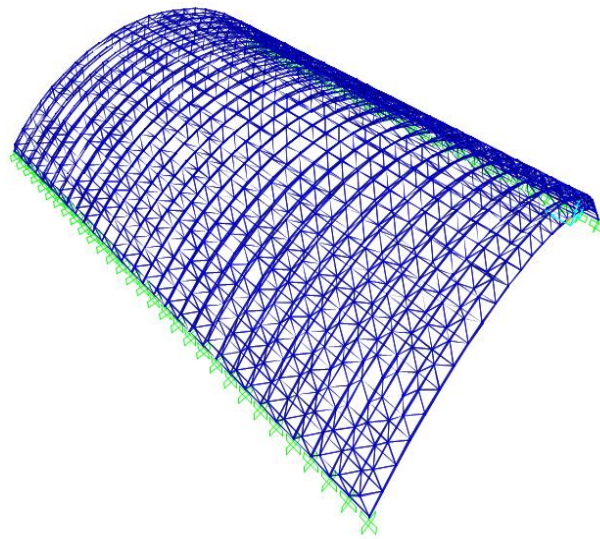

Şekil 4. Örnek sistem 3D görüntüsü 
Tablo 2. Örnek sistem kesit girdileri ve analiz sonuçları

\begin{tabular}{|c|c|c|c|c|c|c|c|c|c|c|c|c|}
\hline \multirow[t]{2}{*}{$\begin{array}{c}\text { Kesit } \\
\text { numarası }\end{array}$} & \multirow{2}{*}{$\begin{array}{l}\text { En } \\
\mathrm{m}\end{array}$} & \multirow{2}{*}{$\begin{array}{c}\text { Yükseklik } \\
\text { m }\end{array}$} & \multirow{2}{*}{$\begin{array}{c}\text { Boy } \\
\mathrm{m}\end{array}$} & \multirow{2}{*}{ 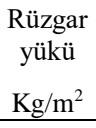 } & \multirow{2}{*}{$\begin{array}{c}\begin{array}{c}\mathrm{Kar} \\
\text { yükü }\end{array} \\
\mathrm{Kg} / \mathrm{m}^{2} \\
\end{array}$} & \multicolumn{2}{|c|}{$\begin{array}{l}\text { Tasarım ivme } \\
\text { katsayıs1 }\end{array}$} & \multirow[t]{2}{*}{ Kesit } & \multirow{2}{*}{$\begin{array}{c}\text { Kesit } \\
\text { boyu } \\
\mathrm{m} \\
\end{array}$} & \multirow{2}{*}{$\begin{array}{c}\mathrm{P} \\
\text { (kuvvet) } \\
\mathrm{kg} \\
\end{array}$} & \multirow{2}{*}{$\begin{array}{c}\text { Kesit kapasite } \\
\text { kullanımı } \\
\% \\
\end{array}$} & \multirow{2}{*}{$\begin{array}{r}\text { Kesit } \\
\text { alan1 } \\
\mathrm{cm}^{2} \\
\end{array}$} \\
\hline & & & & & & $\mathrm{S}_{\mathrm{DS}}$ & $S_{D 1}$ & & & & & \\
\hline 1 & 40 & 10 & 56.5 & 80 & 75 & 0.72 & 0.23 & P7 & 1.88 & -1142.3 & 58 & 8.31 \\
\hline 2 & 40 & 10 & 56.5 & 80 & 75 & 0.72 & 0.23 & P 10 & 1.88 & -13137.1 & 81 & 20.55 \\
\hline 3 & 40 & 10 & 56.5 & 80 & 75 & 0.72 & 0.23 & P7 & 1.68 & -1614.0 & 64 & 8.31 \\
\hline 4 & 40 & 10 & 56.5 & 80 & 75 & 0.72 & 0.23 & P6 & 1.88 & -818.1 & 86 & 6.50 \\
\hline 5 & 40 & 10 & 56.5 & 80 & 75 & 0.72 & 0.23 & P8 & 1.68 & -2557.2 & 57 & 10.80 \\
\hline 6 & 40 & 10 & 56,5 & 80 & 75 & 0.72 & 0.23 & P6 & 1.88 & -846.7 & 89 & 6.50 \\
\hline 7 & 40 & 10 & 56.5 & 80 & 75 & 0.72 & 0.23 & P 10 & 1.88 & -13995.6 & 87 & 20.55 \\
\hline 8 & 40 & 10 & 56.5 & 80 & 75 & 0.72 & 0.23 & P7 & 1.68 & -1744.5 & 70 & 8.31 \\
\hline 9 & 40 & 10 & 56.5 & 80 & 75 & 0.72 & 0.23 & P8 & 1.95 & -1925.0 & 59 & 10.80 \\
\hline 10 & 40 & 10 & 56.5 & 80 & 75 & 0.72 & 0.23 & P6 & 1.88 & -726.5 & 76 & 6.50 \\
\hline
\end{tabular}

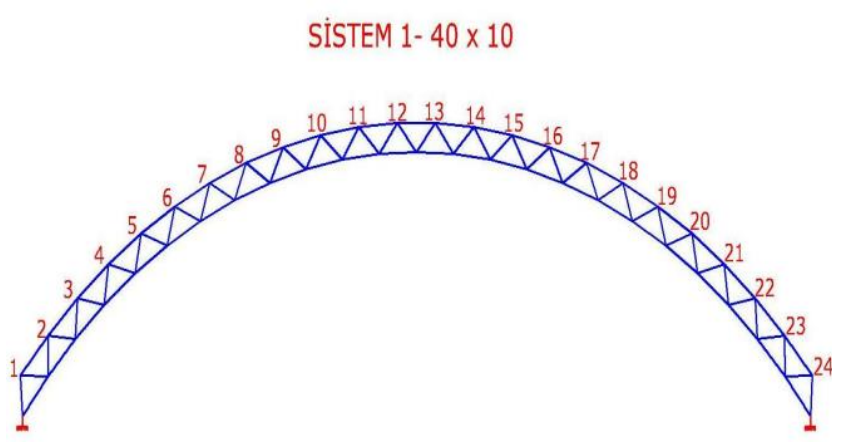

Şekil 5. Örnek sistem 2D görüntüsü

Her sistem için ayrı şekilde hesaplanan ve aşağıda belirtilen yükler kullanılmıştır.

- Zati yük: Uzay kafes sistemin taşıyıcı ve yardımcı elemanlarının zati ağırlıklarıdır.

- Kaplama + aşık yükü: Aşık ve çatı kaplaması zati yükleri hesaplanarak sistemin çatı ile temas halinde olduğu düğüm noktalarından düşey yük olarak etki ettirilmiştir.

- Tesisat Yükü: Uzay kafes sistem üzerindeki mimari açıdan kullanıma hizmet eden aydınlatma, havalandırma kanalları ve tesisatların sistemde oluşturduğu yüklerdir.

- Kar Yükü: Uzay kafes sistemin yapılacağı bölgeye göre TS 498'den [15] yararlanılarak belirtilen yük değerleri alınmış ve yapının çatı eğimine göre her düğüm noktası için ayrı ayrı hesaplanmıştır.

- Rüzgâr Yükü: Rüzgarın etkisi yapı mimarisine, yüksekliğine bağlı hızına, doğrultusuna ve çatının eğimine bağlı olarak TS 498'den [15] yararlanılarak hesaplanmıştır.

- Sıcaklık Etkisi: Sıcaklık etkisi yapının inşa edildiği bölgede sıcaklık farkı dikkate alınarak etki ettirilmiştir.

- Deprem Yükü: Yapının deprem yükü hesaplanırken Türkiye Bina Deprem Yönetmeliği'nden (TBDY-2018) [16] yararlanılarak deprem parametreleri belirlenmiş ve mod birleştirme yöntemi ile sistem analiz edilmiştir.

Yüklemesi tamamlanmış olan çubuklar için malzeme olarak çeliğin yerine cam elyaf takviyeli polyester malzeme kullanılmıştır. Modellemede kullanılan malzeme değerleri aşağıda verilmiştir.

- Birim hacim ağırlık $(\gamma)$

- $\quad$ Elastisite modülü $(\mathrm{E})$

- Poisson oranı $(v)$

- Akma Gerilmesi $\left(\sigma_{f}\right)$

- Çekme dayanımı $\left(\sigma_{\mathrm{d}}\right)$

- Kayma modülü G

- Isıl genleşme katsayısı $(\alpha)$

AISC-ASD89 [7] yönetmeliğine göre yükleme kombinasyonları oluşturularak 240 farklı sistem için tanımlanmış ve analiz edilmiştir. Analizi yapılan 240 farklı tek eğrilikli uzay kafes sistemin boyutlandırılması işlemi CTP yap1 malzemesi, AISC-ASD89 [7] yönetmeliği ve Tablo 3' de verilen kesitler kullanilarak SAP 2000 [6] programı yardımıyla yapılmıştır.

Tablo 2' de kesitler için verilmiş olan girdiler kullanılarak yapılan analiz ve boyutlandırma sonucunda her bir kesit için atanmış bir boru profil, eksenel kuvvet, kesit kapasite oranları ve kesit tam kapasite alanı elde edilmiştir. Sistemlerin her birinde 5760 adet eleman bulunmaktadır. Bu elemanların bazıları basınca bazıları çekmeye çalıştığı görülmüştür. Uzay kafes sistem gereği elemanlarda moment oluşmamaktadır. Bu şekilde 240 farklı sistem ve 5760 kesit düşünüldüğünde toplam 1.382.400,00 adet kesit sonucu elde edilmiştir. Her bir sistem için 5760 adet olan kesit sayısı benzer kesitler örtüştürülerek 73'e düşürülmüş ve 240 farkl1 sistem için toplam 17520 adet kesit data oluşturulmuştur. Elde edilen her bir kesit için atanmış boru profiller, eksenel kuvvetler, kesit kapasite oranları ve kesit tam kapasite alanları incelendiğinde, kesit kapasite oranlarının 0.217 ila 0.950 arasında değişmesi çelik yapılar için kullanılan boru profil kesitlerinin CTP yapı malzemesinden yapılmış boru profillerde de kullanılabileceği ve aynı zamanda tek eğrilikli uzay kafes sistemlerde CTP kullanımının uygun olduğunu göstermektedir. 
Tablo 3. Sistemde kullanılan boru profil kesitlerin özellikleri

\begin{tabular}{cccccc}
\hline Ad1 & $\begin{array}{c}\text { Diş } \\
\text { (cm })\end{array}$ & $\begin{array}{c}\text { Alan } \\
\left(\mathrm{cm}^{2}\right)\end{array}$ & $\begin{array}{c}\text { Atalet } \\
\text { momenti } \\
\text { I }\left(\mathrm{cm}^{4}\right)\end{array}$ & $\begin{array}{c}\text { Mukavemet } \\
\text { momenti } \\
\text { ( }\left(\mathrm{cm}^{3}\right)\end{array}$ & $\begin{array}{c}\text { Atalet } \\
\text { yarıçap1 } \\
\text { i (cm) }\end{array}$ \\
\hline P1 & 2.13 & 1.55 & 0.69 & 0.65 & 0.67 \\
P2 & 2.69 & 2.02 & 1.50 & 1.12 & 0.86 \\
P3 & 3.37 & 3.11 & 3.65 & 2.16 & 1.08 \\
P4 & 4.24 & 4 & 7.71 & 3.64 & 1.39 \\
P5 & 4.83 & 4.6 & 11.73 & 4.86 & 1.60 \\
P6 & 6.03 & 6.5 & 26.18 & 8.68 & 2.01 \\
P7 & 7.61 & 8.31 & 54.67 & 14.37 & 2.57 \\
P8 & 8.89 & 10.8 & 97.42 & 21.92 & 3.00 \\
P9 & 11.43 & 15.53 & 234.41 & 41.02 & 3.89 \\
P 10 & 13.97 & 20.56 & 467.83 & 66.98 & 4.77 \\
P 11 & 16.51 & 24.43 & 784.82 & 95.07 & 5.67 \\
P 12 & 21.9 & 27.03 & 1562.29 & 142.67 & 7.60 \\
P 13 & 21.9 & 33.63 & 1926.12 & 175.90 & 7.57 \\
P 14 & 21.9 & 42.12 & 2383.74 & 217.69 & 7.52 \\
P 15 & 21.9 & 47.28 & 2656.89 & 242.64 & 7.50 \\
P 16 & 21.9 & 53.05 & 2956.62 & 270.01 & 7.47 \\
P 17 & 21.9 & 58.14 & 3216.44 & 293.74 & 7.44 \\
P 18 & 27.3 & 66.63 & 5854.07 & 428.87 & 9.37 \\
P 19 & 27.3 & 73.07 & 6382.60 & 467.59 & 9.35 \\
P 20 & 27.3 & 82.66 & 7156.97 & 524.32 & 9.31 \\
P 21 & 32.39 & 87.15 & 10824.33 & 668.38 & 11.15 \\
P 22 & 32.39 & 98.65 & 12163.24 & 751.05 & 11.10 \\
P 23 & 32.39 & 117.63 & 14325.32 & 884.55 & 11.04 \\
P 24 & 32.39 & 124.21 & 15061.90 & 930.03 & 11.01 \\
P 25 & 33.97 & 130.52 & 17471.74 & 1028.66 & 11.57 \\
P 6 & 35.56 & 136.87 & 20143.56 & 1132.93 & 12.13 \\
\hline
\end{tabular}

2.4 CTP profillerden oluşan tek ĕgrilikli uzay kafes sistemlerin kesit alanlarının YSA ile belirlenmesi

Uzay kafes sistemlerinin statik analizi ve boyutlandırılmasından elde edilen 17520 adet veri çok tabakalı ileri beslemeli geri yayılmalı yapay sinir ağ modelindeki işlemlerde kullanılmıştır. Verilerin \% 70'i modelin eğitilmesi, \% 15'i modelin doğrulaması ve \% 15 'i modelin testi için kullanılmıştır. Çok tabakalı yapay sinir ağ 1 modelinde Tablo 2' de belirtilen 12 farklı girdi değişseni olarak; kesit numarası, sistem genişliği, yüksekliği, uzunluğu, rüzgâr yükü, kar yükü, kısa periyot tasarım spektral ivme katsayısı, 1.0 saniye periyot için tasarım spektral ivme katsayısı, kesitlerin uzunlukları, eksenel kuvvetler, kesit kapasite kullanım oranları ve kesit tam kapasite alanı, çıktı değişkeni olarak da analizler sonucunda elde edilen minimum kesit alanı değerleri kullanılmıştır.

Çok tabakalı ileri beslemeli geri yayılmalı yapay sinir ağı modelinde tek eğrilikli uzay kafes sistemine ait 20 farklı modelin 12 farklı yükleme altında analizi sonucu elde edilen toplam 1382400 adet çubuğa ait kesit alanı içerisinden aynı olanlar örtüştürülmüş ve içlerinden örtüşmeyen 17520 farklı çubuk kesiti kullanılmıştır. Belirlenmiş olan 17520 farklı çubuk kesitine ilişkin değerler. girdi ve çıktı verileri olarak modellerin eğitim, doğrulama ve test kümelerinde kullanılmıştır.

Şekil 6.'da görülen ileri beslemeli geri yayılmalı ağ ve Levenberg-Marquardt öğrenme algoritması kullanılarak iterasyonlarla geliştirilen yapay sinir ağı modelinin eğitim, doğrulama ve test kümelerinden elde edilen sonuçlar, paket program yardımıyla yapılan analiz ve boyutlandırma sonucunda elde edilen minimum kesit alanı değerlerine çok yakındır. Şekil 7'de eğitim, doğrulama ve test sonuçlarının 973 adet döngü için hata grafiği verilmiştir. Bu çalışmada çok tabakalı ileri beslemeli geri yayılmalı yapay sinir ağı modelinde kullanılan parametre değerleri Tablo 4'de verilmiştir.
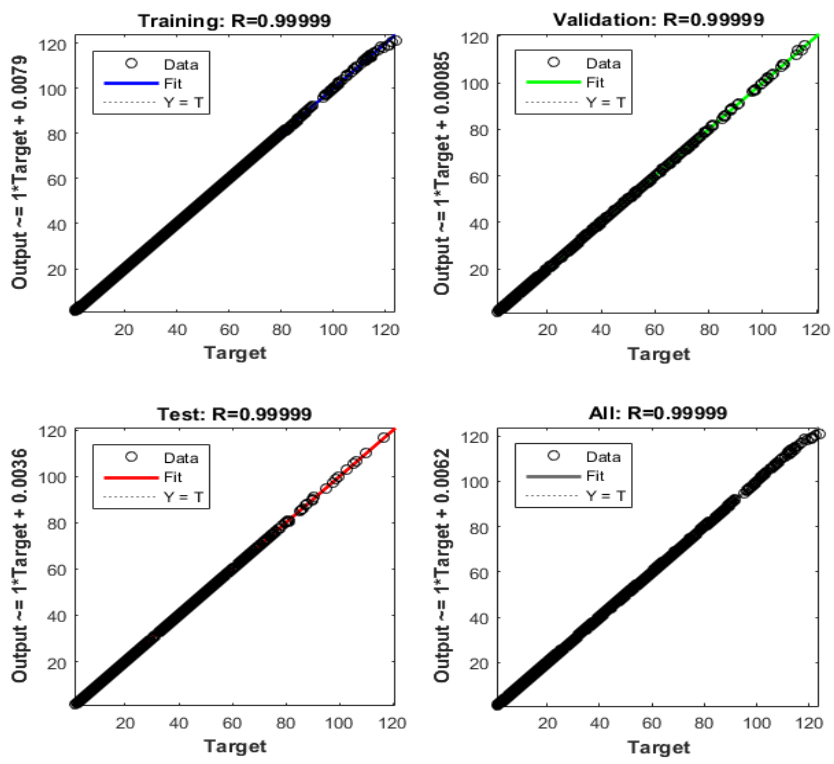

Şekil 6. Eğitim, doğrulama ve test sonuçları ile analiz sonuçlarının karşılaştırılması

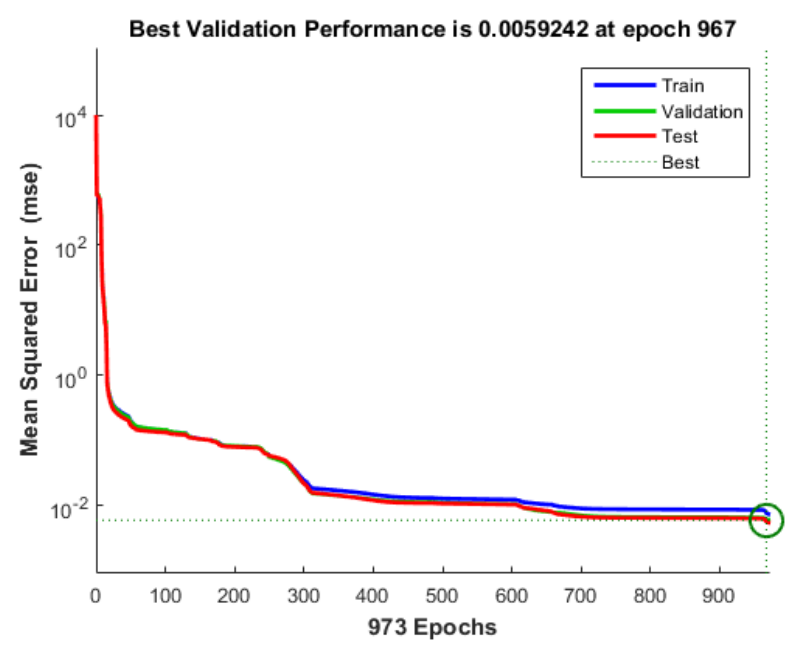

Şekil 7. Eğitim, doğrulama ve test sonuçlarının 973 adet döngü için hata grafiği 
Tablo 4. Tek eğrilikli uzay kafes sistemler için model parametreleri

\begin{tabular}{lc}
\hline \multicolumn{1}{c}{ Parametreler } & YSA \\
\hline Girdi tabakası hücre sayısı & 12 \\
Çıktı tabakası hücre sayısı & 1 \\
Eğitim sonundaki hata & 0.005924 \\
Öğrenme döngüsü & 973 \\
\hline
\end{tabular}

\section{Sonuçlar}

Uzay kafes sistemler bilinen ve kullanılan diğer yapı sistemlerine göre üç boyutlu modüllere ve hafif bir yapıya sahip olmasından dolayı büyük açıklıkları kolonsuz geçebilmektedirler. $\mathrm{Bu}$ özelliğinden dolayı uzay kafes sistemler sergi, konferans, spor salonları, fuarlar gibi insanların kısa süreli fakat yoğun olarak bulunduğu mekânlarda tercih edilmektedir. Fakat bu yapılarda uzay kafes sistem imalatı düzgün yapılmazsa çatı göçmeleri meydana gelebilmektedir. $\mathrm{Bu}$ durum en dikkat edilmesi gereken unsur olarak karşımıza çıkmaktadır.

Uzay kafes sistem elemanlarında yapı malzemesi olarak çelik kullanılmaktadır. Çelik kullanımı da yapıyı ağırlaştırmakta ve bahsedilen göçme tehlikesini arttırmaktadır.

Gelişen cam elyaf takviyeli polyester teknolojisi ile yeni bir yapı malzemesi üretilmiştir. Bu kompozit malzemeyi ön plana iten özelliklerinden en önemlisi hafif olması ve istenilen özelliklerde üretilebilmesidir. $\mathrm{Bu}$ çalışmada tek eğrilikli uzay kafes sistemlerin eleman ihtiyacını karşılayacak hafif, güvenilir, sağlam ve hızlı yapım olanağı bulunan malzemelerden biri olan pultrüzyon metodu ile üretilmiş cam elyaf takviyeli polyester profillerin alternatif bir yapı malzemesi olarak kullanılabilirliği araştırılmıştır. Literatür araştırması ile cam elyaf takviyeli polyesterlerin yapısı, kimyasal, mekanik ve fiziksel özellikleri incelenmiştir. Literatür taramasından elde edilen veriler 1şı̆̆ında yapı malzemesi olarak çelik yerine cam elyaf takviyeli polyesterlerin kullanıldığı tek eğrilikli uzay kafes sistemler modellenmiştir.

Tek eğrilikli uzay kafes sistemler analiz edilirken çelik boru profillerin tablosundaki 26 adet kesit ölçüsü cam elyaf takviyeli polyester profiller için kullanılmıştır. 20 farklı modelin 12 farklı yükleme altında analizi ve AISC-ASD89 [7] yönetmeliğine göre de boyutlandırılması yapılmıştır. Statik analiz ve boyutlandırma sonucunda çelik yapılarda kullanılan 26 adet boru profilin kesitinin cam elyaf takviyeli polyester tipi yapı malzemesi olarak kullanılabildiği görülmüştür.

Statik analiz sonucunda elemanların eğilmeye değil sadece basınç ve çekmeye çalıştığı görülmüştür. Cam elyaf takviyeli polyester profillerin çekme ve basınç dayanımlarının yüksek olmasından dolayı tek eğrilikli uzay kafes sistemlerde kullanılabileceği görülmüştür.

Uzay kafes sistemlerinin statik analizi ve ardından kesitlerin tasarımından elde edilen 17520 adet veri çok tabakalı ileri beslemeli geri yayılmalı yapay sinir ağı modelinin geliştirilmesinde kullanılmıştır. Geliştirilen yapay sinir ağ 1 modelinden elde edilen minimum kesit alan değerlerinin, analiz sonucu elde edilen minimum kesit alan değerlerine çok yakın olduğu görülmüştür. $\mathrm{Bu}$ durumu istatiksel parametre değerleri de göstermektedir.

\section{Çıkar çatışması}

Yazarlar çıkar çatışması olmadığını beyan etmektedir.

\section{Benzerlik oranı (iThenticate): $\% 14$}

\section{Kaynaklar}

[1] T. Y. Soycan, Yapay sinir ağları yaklaşımı ile kompaksiyon parametreleri tahmini. Yüksek Lisans Tezi, Niğde Ömer Halisdemir Üniversitesi Fen Bilimleri Enstitüsü, Niğde, 2008.

[2] E. Özbahar, Tek eğrilikli uzay kafes sistemlerin optimum dizaynı. Yüksek Lisans Tezi, Selçuk Üniversitesi Fen Bilimleri Enstitüsü, Konya, 2007.

[3] M. Sarıbıyı, M. Turhan, A. Sarıbıyı, Cam elyaf takviyeli plastiklerin mekanik özelliklerine elyaf hacim oranlarının etkileri. 5. Uluslararası İleri Teknolojiler Sempozyumu, s. 1-4, Karabük, Türkiye, 13-15 Mayıs 2009.

[4] M. D. Demirbaş, D. Çakır, İki boyutlu fonksiyonel kademelendirilmiş plakaların yapay sinir ağı öğrenme algoritmaları ile ısıl gerilme modellemesi. Niğde Ömer Halisdemir Üniversitesi Mühendislik Bilimleri Dergisi, 9(2), 1065-1076, 2020. https://doi.org/10.28948/ ngumuh. 586770

[5] M. Sarıdemir, İ. F. Kara, Fiberle güçlendirilmiş silis dumanı içeren betonların yarmada çekme dayanımının GEP ile tahmini. Niğde Ömer Halisdemir Üniversitesi Mühendislik Bilimleri Dergisi, 5(2), 208-217, 2016. https://doi.org/10.28948/ngumuh.295586

[6] SAP $2000 \mathrm{v}$ 16, Computers \& Structures, INC, Structural and Eartquake engineering Software.

[7] AISC-ASD89, Allowable Stress Design, American Institute of Steel Construction, Chicago, 1989.

[8] Y. Şahin, Kompozit Malzemelere Giriş, Gazi Yayın Evi, Ankara, 2000.

[9] O. Sayman, S. Aksoy, H. Aykul. An elastic/plastic solution for a thermoplastic composite cantilever beam loading by bending moment, Composite Science and Technology, 60, 2739-2745, 2000. https://doi.org/ $\underline{10.1016 / \mathrm{S} 0266-3538(00) 00146-9}$

[10] İ. Güldü, B. Dağhan ve S. Kaya, Faturalı CTP levhalarda gerilme konsantrasyonun araştırılması. DEÜ Mühendislik Fakültesi Fen ve Mühendislik Dergisi, 5 (2), 27-35, 2003.

[11] A. Cumhur, Pultrüzyon metotu ile üretilmiş CTP profillerle sera modellenmesi. Yüksek Lisans Tezi, Sakarya Üniversitesi Fen Bilimleri Enstitüsü, Sakarya, 2007.

[12] A. Kut, CTP teknolojisi, Cam Elyaf Sanayi A.Ş., Gebze, 2005. 
[13] E. Abadoğlu, M. Ö. Efe and O. Kaynak, Novel analysis and design of a neural network assisted nonlinear controller for a bioreactor. International Journal of Robust and Nonlinear Control, 9 (11), 799-815, 1999. https://doi.org/10.1002/(s1c1)1099-1239(199909)9:11 $<799:$ :a1d-rnc441>3.0.co;2-u

[14] M. F. Keskenler, ve E. F. Keskenler, Geçmişten günümüze yapay sinir ağları ve tarihçesi. Takvim-i Vekayi Dergisi 5 (2), 8-18, 2017.
[15] TS-498, Yap1 elemanlarının boyutlandırılmasında alınacak yüklerin hesap değerleri, Türk Standartları Enstitüsü, Ankara, 1997.

[16] TBDY, Türkiye bina deprem yönetmeliği, Afet ve Acil Durum Yönetimi Başkanlığı, Ankara, 2018. 